\title{
Post-Transplant Diabetes Mellitus and Prediabetes in Renal Transplant Recipients: An Update
}

\author{
Ana Elena Rodríguez-Rodríguez ${ }^{a}$ Esteban Porrinia,b, c Mads Hornum ${ }^{d}$ \\ Javier Donate-Correa ${ }^{\mathrm{e}}$ Raúl Morales-Febles ${ }^{\mathrm{b}}$ Simran Khemlani Ramchand ${ }^{\mathrm{b}}$ \\ María Xixiang Molina Lima ${ }^{b}$ Armando Torres ${ }^{b, c, f}$ \\ ${ }^{a}$ Research Unit, Hospital Universitario de Canarias, Universidad de la Laguna, Tenerife, Spain; ${ }^{\text {b}}$ Faculty of Medicine, \\ Universidad de la Laguna, Tenerife, Spain; 'Instituto de Tecnologías Biomédicas (ITB), Faculty of Medicine, \\ Universidad de la Laguna, Tenerife, Spain; 'Department of Nephrology, Rigshospitalet, University of Copenhagen, \\ Copenhagen, Denmark; ${ }^{e}$ Research Unit, Hospital Universitario Nuestra Señora de Candelaria, Tenerife, Spain; \\ fServicio de Nefrología, Hospital Universitario de Canarias, Tenerife, Spain
}

\section{Keywords}

Post-transplant diabetes mellitus · Prediabetes · Evolution · Pathogenesis

\begin{abstract}
Post-transplant diabetes mellitus (PTDM) is a frequent and relevant complication after renal transplantation: it affects $20-30 \%$ of renal transplant recipients and increases the risk for cardiovascular and infectious events. Thus, understanding pathogenesis of PTDM would help limiting its consequences. In this review, we analyse novel aspects of PTDM, based on studies of the last decade, such as the clinical evolution of PTDM, early and late, the reversibility rate, diagnostic criteria, risk factors, including pre-transplant metabolic syndrome and insulin resistance (IR) and the interaction between these factors and immunosuppressive medications. Also, we discuss novel pathogenic factors, in particular the role of $\beta$-cell function in an environment of IR and common pathways between pre-existing cell damage and tacrolimus-induced toxicity. The relevant role of prediabetes in the pathogenesis of PTDM and cardiovascular disease is also addressed. Finally, current evidence on PTDM treatment is discussed.
\end{abstract}

(C) 2021 S. Karger AG, Basel

\section{Introduction}

Post-transplant diabetes mellitus (PTDM) is a frequent and severe complication after renal transplantation $[1,2]$. PTDM affects $20-30 \%$ of renal transplant recipients and is associated with major complications like cardiovascular and infectious events [3]. Thus, understanding PTDM would help in reducing severe complications after transplantation. During the last decade, several studies evaluated relevant aspects of PTDM like clinical evolution, pathogenesis, and novel therapeutic approaches. In this review, we will analyse previous knowledge and discuss recent findings. Also, we will particularly focus in the clinical consequences of prediabetes and its role in PTDM development and cardiovascular disease in renal transplant recipients.

\section{Diagnosis}

The criteria for defining PTDM are based on those used for diabetes mellitus type 2 (T2DM) in the general population (ADA, WHO) (Table 1) [4]. However, some karger@karger.com www.karger.com/nef (c) 2021 S. Karger AG, Basel
Correspondence to:

Esteban Porrini, esteban.l.porrini@gmail.com 
considerations are pertinent to establish homogeneous criteria of PTDM:

\section{Transient Post-Operative Hyperglycaemia Is Not PTDM}

About $80 \%$ of the patients may experience transient hyperglycaemia early after surgery, which is commonly related to perioperative stress [5]. This should not be confused with PTDM but must be taken into account since it is associated with future development of the disease [6]. Then, the diagnosis of PTDM should be made in clinically stable patients, far from the perioperative period.

\section{Limitations of HbA1c in the Diagnosis of PTDM}

A value of $\mathrm{HbAlc} \geq 6.5 \%$ is a diagnostic criterion for diabetes in the general population [7]. However, the use of $\mathrm{HbAlc}$ after transplantation is not recommended [8]. Anaemia, which is common in the early post-transplant period, may lead to false low HbA1c levels [9]. Moreover, erythropoietin treatment or blood cell transfusions can change $\mathrm{HbA} 1 \mathrm{c}$ levels independently of glycaemic changes $[10,11]$. Therefore, HbAlc should be used with caution and in combination with other criteria like fasting plasma glucose [12].

\section{Oral Glucose Tolerance Test and the Diagnosis of PTDM and Prediabetes}

A standard oral glucose tolerance test (OGTT) consists in the measurement of glucose levels before and after an oral load of $75 \mathrm{~g}$ of glucose. The patient must be with a $10-12 \mathrm{~h}$ fasting and clinically stable, without conditions that can induce transient hyperglycaemia or insulin resistance (IR) like infections, cancer, and cardiovascular events. This test takes only $2 \mathrm{~h}$ and is extremely useful to detect occult glucose abnormalities that coincide with normal fasting glucose levels such as diabetes and impaired glucose tolerance (IGT). In general, PTDM is diagnosed with fasting glucose levels above a threshold. However, it is not unusual that a patient may have normal glucose levels (or in the prediabetic range) whereas the levels at $120 \mathrm{~min}$ are in the diabetic range, that is, $\geq 200$ $\mathrm{mg} / \mathrm{dL}$. In fact, this circumstance accounts for nearly $50 \%$ of the cases with PTDM [13]. So, an OGTT is necessary to detect "occult" PTDM. Also, in subjects with normal fasting glucose, this test allows to detect IGT, a prediabetic condition with plasma glucose values $\geq 140 \quad(7.8$ $\mathrm{mmol} / \mathrm{L})$ and $<200(11.1 \mathrm{mmol} / \mathrm{L})$ which is the most frequent component of prediabetes [13]. IGT is a risk factor for PTDM and contributes to the impact of hyperglycaemia on cardiovascular disease in this population $[14,15]$.
Table 1. Diagnostic criteria for diabetes mellitus and prediabetes by the ADA

\begin{tabular}{ll}
\hline $\begin{array}{l}\text { Diabetes } \\
\text { RPG }\end{array}$ & $\geq 200 \mathrm{mg} / \mathrm{dL}(11.1 \mathrm{mmol} / \mathrm{L})$ \\
FPG & $\geq 126 \mathrm{mg} / \mathrm{dL}(7 \mathrm{mmol} / \mathrm{L})$ \\
2hPG & $\geq 200 \mathrm{mg} / \mathrm{dL}(11.1 \mathrm{mmol} / \mathrm{L})$ \\
HbAlc & $\geq 6.5 \%$ \\
\hline Prediabetes & \\
IFG & FPG $100-126 \mathrm{mg} / \mathrm{dL}(5.6-6.9 \mathrm{mmol} / \mathrm{L})$ \\
IGT & FPG $<126 \mathrm{mg} / \mathrm{dL}(7 \mathrm{mmol} / \mathrm{L})$ \\
& $2 \mathrm{hPG} 140-200 \mathrm{mg} / \mathrm{dL}(7.8-11 \mathrm{mmol} / \mathrm{L})$ \\
Increased risk of & HbAlc $5.7-6.4 \%$ \\
diabetes & \\
\hline $\begin{array}{l}\text { Normal glucose } \\
\text { tolerance }\end{array}$ & FPG $<100 \mathrm{mg} / \mathrm{dL}(5.6 \mathrm{mmol} / \mathrm{L})$ \\
& $2 \mathrm{hPG}<140 \mathrm{mg} / \mathrm{dL}(7.8 \mathrm{mmol} / \mathrm{L})$ \\
& $\mathrm{HbA} 1 \mathrm{c}<5.7 \%$
\end{tabular}

ADA, American Diabetes Association; RPG, random plasma glucose; FPG, fasting plasma glucose; $2 \mathrm{hPG}, 2$-h plasma glucose after an oral glucose; IFG, Impaired fasting glucose; IGT, impaired glucose tolerance.

- PTDM must be diagnosed in clinically stable patients, applying standard criteria for diabetes. The use of $\mathrm{HbA1c}$ alone is not recommended. OGTT is a simple test that provides useful information like the diagnosis of occult diabetes and prediabetes. So, it must be implemented in day-to-day clinical practice after renal transplantation.

\section{Epidemiology: Prevalence, Incidence, and Evolution over Time}

\section{Post-Transplant Diabetes Mellitus}

Using the diagnostic criteria shown in Table 1, the prevalence of PTDM varies from 20 to $30 \%$ at different time points after transplantation [13]. A prospective cohort of $>600$ subjects without diabetes at pre-transplant who underwent repeated OGTTs ( 3 months and annually) showed a prevalence at 3 months of 27,26 , and $47 \%$ for PTDM, prediabetes, and normal glucose tolerance, respectively. These figures remained stable during 3-5 years. Thus, about half of the subjects had either PTDM or prediabetes, pointing to the high frequency of these complications. Similar findings were observed in other studies [16-18]. As indicated above, an OGTT was necessary to detect about half of the cases of PTDM, which reinforces the role of this test in clinical practice. 
Fig. 1. Timeline of risk factors for PTDM. The risk factors for PTDM have been classified as "pre-transplant" and "post-transplant," depending on whether they appear before or after transplant. The line represents the incidence of PTDM, including new cases and excluding those that reverse their diabetes. Figure adapted from reference [13]. PTDM, post-transplant diabetes mellitus; MS, metabolic syndrome.

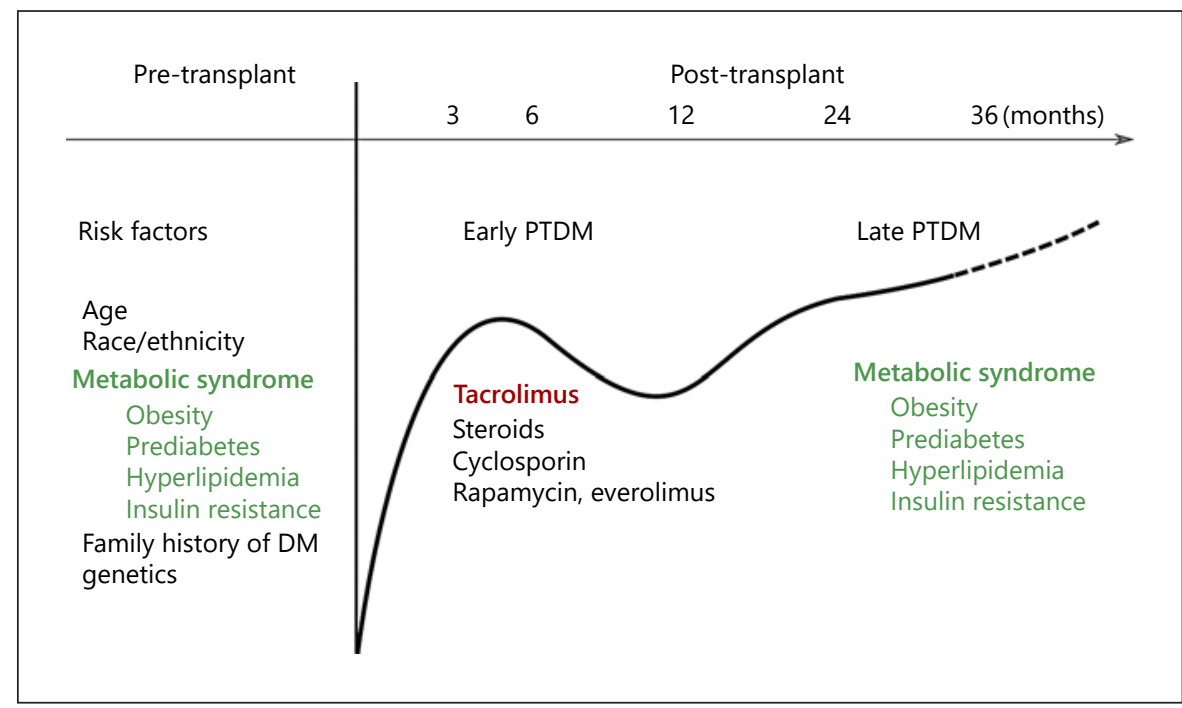

\section{Prediabetes}

The prevalence of prediabetes after transplantation is variable and varies around $20 \%$ at different time points [13]. Of them, about half of the cases are IGT, $30 \% \mathrm{im}-$ paired fasting glucose (IFG), and 20\% may have the combination of both: IFG + IGT. Half of the cases of prediabetes, that is, IGT, could be diagnosed only by an OGTT (Table 2).

\section{Clinical Evolution of PTDM and Prediabetes}

Early and Late PTDM

The majority of the cases of PTDM (about 70-80\%) are observed early after transplantation, that is, 3-6 months - early PTDM - and the remaining cases develop during follow-up - late PTDM - (from 12 months onwards) [13, 19] (Fig. 1). This evolution is bimodal: 20$30 \%$ of early PTDM may revert into normal or prediabetes in the following months [13]. Reversibility of PTDM is mainly observed during the first 24 months. Finally, the annual incidence of late PTDM is similar to that observed in patients with prediabetes in the general population, $\sim 7 \%[13,19]$.

\section{Evolution of Prediabetes}

During follow-up, prediabetes (IGT or IFG) may persist in about $40 \%$, normalize in $40 \%$, or evolve into PTDM (late PTDM) in $20 \%$ of recipients [13] (Fig. 1).

- Thus, both prediabetes and PTDM are unstable conditions. This indicates relevant plasticity in $\beta$-cell that allows recovering after damage. Also, reversibility rate of PTDM and prediabetes must be taken into account in the design of clinical trials, to discriminate between the effects of therapies from spontaneous reversibility.

\section{Risk Factors}

Not all renal transplant patients will develop PTDM. Traditionally, risk factors for PTDM have been classified as "modifiable" and "non-modifiable" or "pre-transplant" and "post-transplant" and have been discussed elsewhere [20, 21] (Fig. 1).

\section{Pre-Transplant Risk Factors: Early Identification of \\ Patients at Risk}

\section{Metabolic Syndrome}

Many of the pre-transplant risk factors are common to those of T2DM. These include age, non-Caucasian ethnicity, family history of diabetes, and metabolic factors like obesity, dyslipidaemia, and prediabetes (Fig. 1). These metabolic factors frequently coincide in the socalled metabolic syndrome (MS), a classic risk factor for T2DM. Interestingly, MS is observed in $25-35 \%$ of the patients on dialysis [21-24], which indicates that 1 patient in 3 or 4 in the waiting list for transplantation may be at risk for diabetes. In fact, Bayer et al. [25], in 640 nodiabetics patients, observed that pre-transplant MS as well as its single components increased the risk for PTDM. Similar results have been reported in more recent studies [26]. 
Occult Diabetes and Prediabetes in the Waiting List Population

Prediabetes (IFG and or IGT) is especially frequent in this population. Bergrem et al. [27] in 889 patients observed that $37 \%$ had prediabetes $(25.9 \%$ IGT and 11.2 IFG), which is larger than in the general population. Also, the prevalence of occult diabetes (unmasked with an OGTT) was $6 \%$. Similar results were observed by other groups [28]. Thus, a non-negligible number of patients in the waiting list can have 2 major risk factors for PTDM, pre-transplant prediabetes or occult diabetes. As indicated above, many of these cases are only diagnosed by an OGTT. Unfortunately, these risk factors are rarely evaluated in patients in the waiting list for transplantation.

- MS and prediabetes are modifiable risk factors, which may help in reducing the incidence of PTDM by applying pre-transplant interventions or selecting a less diabetogenic immunosuppression. The identification of pre-transplant risk factors is crucial to select those patients really at risk for PTDM. In clinical trials, the inclusion of patients not at risk, that is, those with normal weight, no MS, may jeopardize the results of the study.

\section{Post-Transplant Risk Factors: The Crucial Role of Immunosuppression}

Post-transplant risk factors are specific of the renal transplant population and include the immunosuppressive drugs, that is, steroids, tacrolimus or cyclosporin A and rapamycin or everolimus, certain alleles of human leukocyte antigens such as HLA A30, B27, and B42, and the type of renal disease like polycystic kidney disease $[26,29,30]$ (Fig. 1). Evidently, the immunosuppressive therapy represents the main post-transplant risk factor for PTDM and has been extensively reviewed previously $[29,30]$ (Fig. 1). Most of the available literature covers the impact of steroids, calcineurin inhibitors, and mammalian target of rapamycin (mTOR) inhibitors in the incidence of PTDM. Recently, other new immunosuppressants have emerged as an alternative to calcineurin inhibitors. Belatacept is a selective $\mathrm{T}$ lymphocyte co-stimulation blocker. The clinical trials, BENEFIT and BENEFIT-EXT, have shown that belatacept preserves function and structure in renal grafts and that its effects are maintained in the long term $[31,32]$. In a retrospective study of 50,244 patients, clinical outcomes at 1 year were compared between belatacept and tacrolimustreated renal transplant recipients. The incidence of PTDM was significantly lower with belatacept plus tacrolimus and belatacept alone versus tacrolimus alone
$(1.7,2.2$, and $3.8 \%$, respectively; $p=0.01)$ [33]. In this review, we will focus in the pathways involved in $\beta$-cell toxicity associated with the use of the immunosuppressive treatment, mainly tacrolimus.

\section{Pathogenesis}

PTDM is a complex and multifactorial disease that in several aspects resembles T2DM. Its pathogenesis involves genetic, environmental, and physiological factors $[34,35]$. On top of this variable background, immunosuppressive therapy triggers the appearance of PTDM. The interaction between all these factors is crucial to understand the pathogenesis of PTDM.

\section{MS and IR at Pre-Transplant: Unmasking $\beta$-Cell Dysfunction}

The high prevalence of MS in patients in the waiting list is crucial to understand the pathogenesis of PTDM. Although the background of MS is not clearly established, Reaven GM proposed IR as the main force linking obesity, hypertension, dyslipidemia, and prediabetes [36]. IR is not a condition easily defined. In accordance with Kahn, IR is "any situation where the ability of insulin to exert its biological actions on the target tissues (skeletal muscle, liver, and/or adipose tissue) is diminished" [37]. Importantly, both IR and MS frequently precede the development of diabetes in the general population [38-40]. IR has always been considered a peripheral condition affecting insulin response and glucose metabolism in the liver, skeletal muscle, and adipose tissue. Importantly, these changes have been documented after renal transplantation [41, 42]. However, several studies also showed a clear impact of peripheral IR on $\beta$-cell function $[43,44]$. The reduced action of insulin leads to mild hyperglycaemia (prediabetes) and a compensatory increase of insulin secretion and hyperinsulinemia. This status cannot endure, causes $\beta$ cell dysfunction, and eventually cell death. In fact, De Fronzo et al. $[43,44]$ showed that $\beta$-cell function decreases progressively in subjects with prediabetes compared with those with normal glucose metabolism. Interestingly, $\beta$-cell function diminished up to $80 \%$ in patients with prediabetes (IGT) $[43,44]$. Similar changes have been reported in patients with uraemia [45].

- Thus, patients in the waiting list with MS may have a certain degree of $\beta$-cell dysfunction/damage induced by IR, which facilitates the toxicity of immunosuppressant therapy. 


\section{$\beta$-Cell Dysfunction and Damage in the IR State at}

\section{Pre-Transplant}

IR precedes the development of T2DM in about 10-20 years [46]. During this period, the function of $\beta$ cells deteriorate progressively due to factors like glucolipotoxicity, impaired insulin biosynthesis and secretion, $\beta$-cell mass reduction, exhaustion, or overwork [47-49]. In a necropsy studies, $\beta$-cell mass was $50 \%$ lower in patients with T2DM compared with non-diabetics [50]. Other groups observed similar results $[51,52]$. Although the reduction in $\beta$ cells' mass was attributed to apoptosis, the percentage of cell death was modest compared to the functional damage [50]. Therefore, other mechanisms different from apoptosis may be involved in the transition towards diabetes. Recent studies proposed $\beta$-cell dedifferentiation as a mechanism of cell damage in diabetes [53, 54]. In this process, the cell returns to a less specialized state within the same linage and can be considered a mechanism of defence against glucolipotoxicity, oxidative and endoplasmic reticulum stress, mitochondrial dysfunction and inflammation. Throughout dedifferentiation, cells do not die but lose its special form or function, changing to an earlier developmental stage. The processes cause alterations in key transcription factors such as MafA, FoxO1, PDX1, and NeuroD1 amongst others [53]. MafA is involved in the maintenance of mature $\beta$ cells and together with PDX1 and NeuroD1 binds directly to the insulin gene promoter [55-57]. FoxO1 is a regulatory factor of multiple processes such as differentiation, proliferation, apoptosis, cell metabolism, and response to cellular stress [58]. Evidence on this theory came from studies showing that changes in these factors may lead to $\beta$-cell dysfunction and T2DM [59]. Talchai et al. [53], using mice lacking FoxO1 in $\beta$ cells, observed a progressive loss of PDX1, MafA, and the appearance of typical markers of undifferentiated cells, that is, as neurogenin-3 or Oct4. Wang et al. [60], in a KATP-dependent diabetes model, demonstrated that dedifferentiation rather than apoptosis was a main mechanism of $\beta$-cell dysfunction and that insulin therapy induced re-differentiation of these cells. Thus, the dedifferentiated $\beta$-cell may re-differentiate to a normal cell if the toxic damage is resolved or attenuated. Spijker et al. [61], in a model of islet cell aggregate formation, observed that human $\beta$ cells could become glucagon-producing a cells.

- The "dedifferentiation theory" established a new pathway of $\beta$-cell dysfunction in diabetes. On the other hand, the recovery of their original status after the removal of toxic factors indicates that these cells are more resilient and plastic than originally thought.
Interaction between Pre-Transplant and Post-Transplant Risk Factors for PTDM

PTDM induced by tacrolimus or cyclosporine A is particularly common amongst patients with pre-transplant risk factors for diabetes, that is, obesity and dyslipidaemia. Also, some MS traits like dyslipidaemia are useful to discriminate the different toxic effect of tacrolimus compared to cyclosporine. Porrini et al. [62], in a study of 314 renal transplant recipients, observed that tacrolimus was more diabetogenic than cyclosporine, only when given to patients with high levels of triglycerides in the waiting list. Importantly, high triglyceride levels is a marker of MS and IR.

- Calcineurin inhibitors are especially toxic in subjects with MS in the waiting list.

\section{Immunosuppressive Therapy: An Accelerator of an Existing Damage}

$\beta$-cell damage induced by the immunosuppressive drugs has been analysed in animal and cell models. Tacrolimus and cyclosporine A impaired insulin secretion, decreased insulin content and insulin transcription [6366]. To analyse the interaction between previous $\beta$-cell damage induced by MS-IR with tacrolimus or cyclosporine A, Rodriguez-Rodriguez et al. [67] used a model of IR, the obese Zucker rat (fa/fa), and their insulin-sensitive counterpart, the lean Zucker rat (fa/-). No lean animals either on tacrolimus or cyclosporine A developed diabetes whereas all obese animals on tacrolimus and only $40 \%$ on cyclosporine A did. This result is in line with the idea that pre-existent damage facilitates the toxic effect of calcineurin inhibitors, as observed in humans [62]. Tacrolimus-induced diabetes in obese animals was associated with reduced $\beta$-cells proliferation, no apoptosis and relevant changes in nuclear factors like MafA and FoxO1. In obese animals without CNIs, the nuclear expression of MafA decreased and that of FoxO1 increased and these changes were exacerbated with tacrolimus. These results were confirmed in an in vitro model of $\beta$-cells [68]. Interestingly, tacrolimus withdrawal or conversion to cyclosporine A partially reverted these changes [68]. These results support studies in humans in which PTDM was reduced to $40 \%$ after switching from tacrolimus to cyclosporine A, even after 1 year of treatment $[69,70]$. This may indicate different mechanisms of damage besides the calcineurin inhibitory capacity [67].

Tacrolimus may also affect more pathways in $\beta$-cells than cyclosporine A. A possible clue of this diverse action may be FKBP12, the immunophilin of tacrolimus, 
which is involved in multiple cellular processes [71]. FKBP12 regulates transforming growth factor $\beta$ family type-I receptors, that is, BMP $[72,73]$, stabilizes calcium channel ryanodine receptor 2 of the endoplasmic reticulum [74], and interacts with the mTOR pathway. A recent study showed that TAC partially inhibits the mTOR pathway, although to a lesser extent than its main inhibitor rapamycin [75]. On the other hand, Triñanes et al. [76] showed that TAC interacts with SMADs and FoxO1 signalling during metabolic stress characteristics of IR in $\beta$-cells human islets. Thus, pathways related to FKBP12 could be modified by tacrolimus and so associated with the diabetogenic effect of tacrolimus in the context of IR.

- Obesity, IR and tacrolimus may induce the same changes in $\beta$-cells described in the "dedifferentiation theory." Moreover, the reversibility of PTDM after tacrolimus withdrawal both in animals and humans support this pathway of cell damage.

\section{$\beta$-Cell Centric View: Towards a Comprehensive}

Hypothesis of PTDM

In general, PTDM is considered a fait accompli: an irreversible consequence of the anti-rejection therapy. However, our vision is that PTDM does not depend only on immunosuppression. Pre-existing $\beta$-cell damage related to IR makes these cells especially vulnerable to tacrolimus, cyclosporine A, steroids. So, pre-transplant $\beta$-cell function is a relevant and necessary player in the pathogenesis of PTDM. $\beta$-cell functional evaluation can be complex and there is no accurate and precise way to determine the level of $\beta$-cell damage. However, MS and IR could be considered simple markers of a dysfunctional cell, indicating predisposition to damage.

Thus, in accordance with the $\beta$-cell-centric view of PTDM (Fig. 2), in 3 possible groups, those with (a) normal $\beta$ cells and so, normal glucose metabolism, in whom the immunosuppression therapy is not supposed to induce cell damage; (b) moderate dysfunctional $\beta$-cells, in patients with IR and prediabetes, in whom cells could compensate for the toxic damage leading to persistent prediabetes after transplantation; and (c) advanced $\beta$-cell damage, in subjects with IR and prediabetes, in whom cells are not able to compensate the toxic damage leading to early PTDM. Finally, the toxic conditions may change 3-6 months after transplantation and this can induce further changes in $\beta$-cell function. The use of lower doses of TAC and the stabilization of renal function may promote the reversibility of damage in cells with moderate dysfunction, leading to the reversibility of PTDM to prediabetes or even normal glucose metabolism or from prediabetes to normal glucose metabolism. In patients with early PTDM and advanced pre-transplant cell damage, the exposure to lower doses of TAC may not be enough to reverse diabetes (Fig. 2).

This view of the pathogenesis of PTDM is not intended to be dogmatic or exclusive. It is, as all visions of the pathogenesis of a disease, simplistic, in order to understand a complex process in human biology. We do not want to exclude other factors. This view is clearly orientated to highlight the relevance of pre-transplant $\beta$-cell function and its interaction with post-transplant risk factors.

\section{Role of Peripheral IR after Transplantation in the} Appearance of PTDM

Clearly, $\beta$-cell dysfunction is not the only player in the pathogenesis of diabetes. IR is a risk factor for the development of T2DM in the general population [36]. Its consequences in renal transplantation are not clearly established but both IR and insulin deficiency are necessary for the appearance PTDM. In renal transplant recipients, IR is highly prevalent. Midtvedt et al. [77] observed that IR is a common denominator of PTDM and IGT. Erkstrand et al. [78] observed that renal transplant recipients are more insulin resistant than healthy subjects. In the same line, Hornum et al. [41] found, at 1 year after renal transplantation, PTDM was present in $14 \%$ of patients and was associated with IR. In other study, Jørgensen et al. [42] observed that insulin sensitivity was reduced 6 months after renal transplant, and this was mainly explained by impaired suppression of endogenous glucose production. Few studies have evaluated the possible causes of IR in transplant population. Oterdoom et al. [79], in a crosssectional study, observed that age, male gender, BMI, prednisone dose, and renal function were associated with lower insulin sensitivity. Many patients receive steroids at doses that are usually higher during the first semester, gradually decreasing until the first year. Accordingly, 10 $\mathrm{mg}$ of prednisone may induce up to a $250 \%$ increase in insulin demand [80]. Different studies in the transplant population have observed the association between steroid use and IR [81]. The other drugs used in transplantation, like calcineurin inhibitors (tacrolimus and cyclosporine) and rapamacyn, have also been associated with an increase in IR [82-85]. Thus, as happens for T2DM in the general population, IR has certainly a role in the pathogenesis of PTDM. 


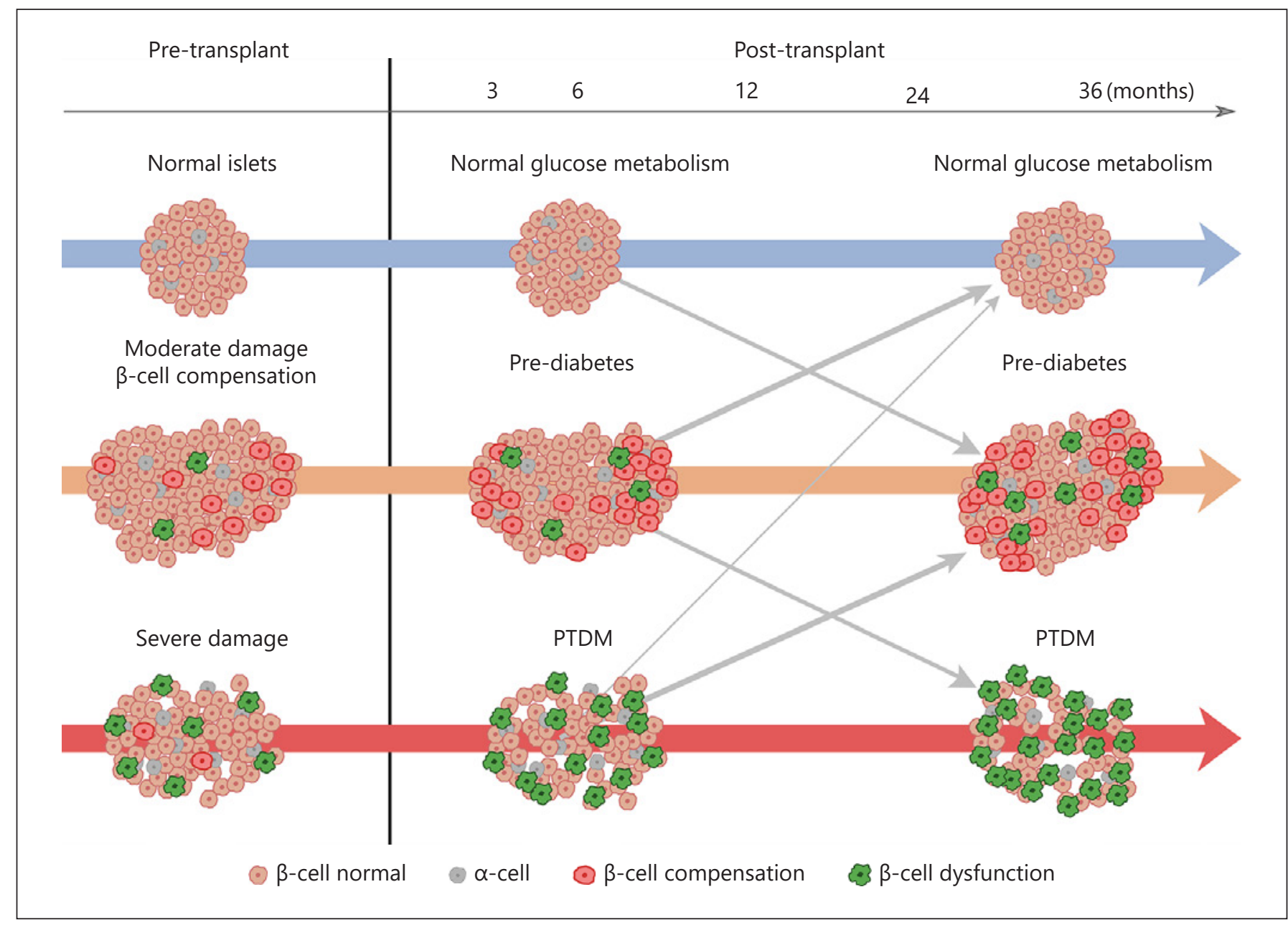

Fig. 2. Evolution of PTDM according with the pre-transplant $\beta$-cell damage. Non-diabetic patients in the waiting list could be classified in those with (a) normal $\beta$-cells: normal glucose metabolism, in whom the immunosuppression after transplantation does not induce cell damage; (b) moderate dysfunctional $\beta$-cells: in patients with IR and prediabetes, in which cells could compensate for the toxic damage leading to persistent prediabetes after transplanta-

\section{Consequences of Prediabetes and PTDM in Renal Transplant Recipients}

Different studies evaluated the impact of PTDM on major outcomes after transplantation, that is, fatal and non-fatal cardiovascular events, all-cause mortality, graft failure censored for death with a functioning graft, and infectious diseases. PTDM is associated with a $2-4$ fold increased risk for fatal and non-fatal cardiac events [8688]. In the same line, prediabetes has been recently associated with cardiovascular disease in renal transplantation. Porrini et al. [89] performed a 8-year follow-up tion; and (c) advanced cell damage: in subjects with prediabetes, in whom $\beta$-cells are not able to compensate the toxic damage, leading to early PTDM. After 3-6 months, prediabetes or PTDM may normalize or remain stable. Also patients with prediabetes may develop late PTDM. Finally, patients with normal glucose metabolism may develop new-onset prediabetes. PTDM, post-transplant diabetes mellitus. 
tentially prevent future cardiac events. Another issue is whether and how patients with prediabetes should be treated, by diet modification, guided exercise or anti-diabetic medication. Randomized, multicentre trials should be performed to establish the optimum management.

PTDM also increases the risk of infectious complications [3]. On the other hand, the relationship between PTDM and other major outcomes like graft failure and cancer remains controversial. Some studies did not observe a clear relationship between PTDM and graft loss [3]. Recently, Yeh et al. [19], in a retrospective analysis of 3,663 kidney transplant recipients, 631 (17\%) with PTDM, observed that PTDM was associated with a higher risk for death-censored graft loss (HR 1.65, 95\% CI 1.47-1.85). Clearly, this association must be confirmed in future ad hoc designed studies. Finally, there is a lack of information about a possible relationship between PTDM and cancer, a major cause of morbidity in renal transplant patients. In the general population, T2DM is associated with a $20-25 \%$ increased risk of common cancers, that is, colorectal, postmenopausal breast, endometrial, liver, pancreatic, bladder, and non-Hodgkin's lymphoma amongst the most relevant [90-92]. Moreover, the severity of certain cancers is larger in patients with diabetes, with a greater early and late mortality compared with non-diabetic patients with cancer $[90,91]$. Also, prediabetes, obesity and MS have been associated with increased incidence of cancer [90-92]. So, it is plausible to speculate that PTDM and obesity could be associated, at least in part, with the increased incidence of cancer that characterizes the renal transplant population. However, this issue has been largely under investigated. Yeh et al. [19], in a retrospective analysis, found that PTDM was associated with an increased risk for cancer-related death (HR.1.56 [1.18-2.07]) [19]. This finding was not evaluated by other studies. In any case, taking into consideration the high risk for cancer in the transplant population, the possible link between PTDM, obesity, and MS with post-transplant cancer deserves detailed investigation by ad hoc designed studies.

\section{Treatment and Prevention}

\section{Prevention of PTDM}

As indicated above, the identification of patients at risk for PTDM both before and after transplantation may help in preventing PTDM. MS in the waiting list is established risk factors for PTDM [25]. This offers 2 possibilities: either to treat patients with MS in the waiting list to im- prove $\beta$-cell dysfunction before transplantation or to identify these patients and select a less diabetogenic therapy after transplantation. To the best of our knowledge, no evidence is available on the effect of active interventions in patients at risk for PTDM in the waiting list for transplantation. At least theoretically, exercise may increase insulin sensitivity and reverse some of the traits of MS in patients on dialysis. However, no study has evaluated the impact of exercise or other interventions in the reversibility of the risk profile for PTDM in patients in the waiting list for transplantation, a topic that is worth investigating.

By the other hand, a recent clinical trial analysed the impact of a less diabetogenic immunosuppression in patients at risk for PTDM in the waiting list based on metabolic criteria [93]. In brief, a total of 128 subjects were randomized to tacrolimus plus rapid steroid withdrawal within 1 week, and tacrolimus or cyclosporine A with steroid minimization [93]. All 3 arms received basiliximab and mycophenolate mofetil. The cyclosporine A arm showed the lower 1-year incidence of PTDM (10\%) but with a $21 \%$ acute rejection rate. Of relevance, tacrolimusbased immunosuppression with steroid minimization (5 $\mathrm{mg}$ of prednisone from week 5 onwards), resulted in the best balance between acute rejection and PTDM (5\% and $26 \%$, respectively) [93]. This could be a reliable approach to reduce the incidence of early PTDM, which represents the majority of the cases of PTDM, without affecting the efficacy. Clearly, more studies in this line are needed to individualize the immunosuppression in patients at risk for diabetes.

Finally, intervention studies designed to prevent late PTDM are lacking. The vast majority of the cases of late PTDM are observed in patients with prediabetes after transplantation [13]. Since prediabetes is potentially reversible, interventions may eventually prevent PTDM by treating patients with this complication. In the nontransplant population, exercise, diet, or pharmacological interventions, that is, metformin, proved to effectively prevent the incidence of diabetes in patients with prediabetes [94-96]. Similar studies in the renal transplant setting are lacking. The TRANSDIAB (transplantation and diabetes) study evaluated the feasibility and safety of metformin in patients with prediabetes after transplantation. The authors concluded that the use of metformin was safe in this population. However, the study had not power enough to prove efficacy. More studies are needed to evaluate the role of metformin, a very cheap medication, in the prevention of PTDM in patients at risk. On the other hand, there is no definitive evidence on the capacity of 
Table 2. Active and recent (within 3 years) pre-diabetes and PTDM studies registered on clinicaltrials.org

\begin{tabular}{|c|c|c|c|c|}
\hline $\begin{array}{l}\text { Clinicaltrials.org } \\
\text { identifier }\end{array}$ & Study completion & Title of project & Study narrative & Conditions \\
\hline NCT03642184 & December 2020 & $\begin{array}{l}\text { Efficacy and Safety of Empagliflozin in } \\
\text { NODAT }\end{array}$ & $\begin{array}{l}\text { Open label RCT testing of empagliflozin } \\
\text { versus linaligliptine for treatment of } \\
\text { New Onset Diabetes After Kidney } \\
\text { Transplantation }\end{array}$ & $\begin{array}{l}\text { New Onset Diabetes } \\
\text { After Transplant } \\
\text { Kidney Transplant; } \\
\text { Complications }\end{array}$ \\
\hline NCT03507829 & May 2018 & $\begin{array}{l}\text { Insulin Therapy for the Prevention of } \\
\text { New Onset Diabetes After Transplan- } \\
\text { tation (ITP-NODAT) Prospective } \\
\text { Study in Non-Diabetic De Novo Kid- } \\
\text { ney Transplant Recipients }\end{array}$ & $\begin{array}{l}\text { Open label RCT comparing aggressive } \\
\text { glycemic control with early institution } \\
\text { of insulin therapy to standard of care }\end{array}$ & Hyperglycemia \\
\hline NCT02849899 & October 2020 & $\begin{array}{l}\text { Prevention of New Onset Diabetes } \\
\text { After Transplantation by a Short Term } \\
\text { Treatment of Vildagliptin in the Early } \\
\text { Post-transplant Period }\end{array}$ & $\begin{array}{l}\text { Open label RCT comparing early treat- } \\
\text { ment with Vildagliptin to placebo }\end{array}$ & $\begin{array}{l}\text { Disorder Related to } \\
\text { Renal Transplantation } \\
\text { Diabetes }\end{array}$ \\
\hline NCT01680185 & May 2018 & $\begin{array}{l}\text { Treat-To-Target Trial of Continuous } \\
\text { Subcutaneous, Sensor-Augmented } \\
\text { Insulin-Pump Therapy in New-onset } \\
\text { Diabetes After Transplantation } \\
\text { (SAPT-NODAT) }\end{array}$ & $\begin{array}{l}\text { Open label study of intensive subcuta- } \\
\text { neous insulin treatment with short } \\
\text { acting insulin, applied continuously } \\
\text { through an insulin pump in comparison } \\
\text { to a standard of care control group }\end{array}$ & Hyperglycemia \\
\hline NCT03961256 & June 2021 & $\begin{array}{l}\text { A Phase 2, Prospective, Randomized, } \\
\text { Multicenter, Open-Label, Controlled } \\
\text { Trial to Assess the Efficacy and Safety } \\
\text { of Exenatide SR for the Prevention of } \\
\text { Diabetes After Kidney Transplanta- } \\
\text { tion }\end{array}$ & $\begin{array}{l}\text { Open label RCT to determine if Exena- } \\
\text { tide SR, is well tolerated in kidney trans- } \\
\text { plant patients with elevated blood glu- } \\
\text { cose levels, and if it's effective in pre- } \\
\text { venting diabetes }\end{array}$ & Pre Diabetes \\
\hline
\end{tabular}

therapeutic exercise in preventing PTDM. To the best of our knowledge, there is one study ongoing: EXPRED (Exercise and Prediabetes after Transplantation) testing the capacity of exercise to reverse prediabetes in patients at least 12 months after transplantation [107]. The results may show the reliability of exercise in preventing late PTDM.

\section{Treatment of Established PTDM}

The treatment of PTDM follows the usual guidelines for identifying and guiding patients with hyperglycaemia after transplantation, that is, early referral to an endocrinologist for evaluation and guidance in the choice of treatment. In the early period after transplantation, insulin is the preferable choice of treatment, with life-style modification and oral anti-diabetic therapy being the next step in the consensus treatment algorithm [97]. Previous studies demonstrated that aggressive anti-hyperglycaemic therapy with insulin, early ( $<3$ weeks) after kidney transplant, lowered the risk for developing PTDM after 1 year [98] and the results of a following study, ITPNODAT, using insulin pump technology to treat NODAT, is expected [99]. Both recent and ongoing trials on PTDM are depicted in Table 2.

Both vildagliptin and sitagliptin, which are DPP-4 inhibitors, have been shown to be safe in small studies [100102]. Furthermore, GLP-1 receptor agonists are at present only evaluated in a case series and a proof of concept study $[103,104]$ but an interesting phase-II, open-label, randomized study with exenatide started 4-6 months af- 
ter kidney transplantation is underway (NCT03961256) with the goal to prevent prediabetes from developing to PTDM after 1 year. Also, small studies with SGLT-2 inhibitors are performed as a safe anti-diabetic therapy $[105,106]$, and further studies of empagliflozin versus linagliptin (NCT03507829) and the PRODIG study, vildagliptin in a tapered dosing schedule for 3 months versus placebo (NCT02849899) are awaited.

Finally, a recent clinical trial evaluated the efficacy and safety of the change to cyclosporine in patients with tacrolimus-induced PTDM [69]. Wissing et al. [69], included 87 patients with PTDM who were randomized to change to cyclosporine A or continue with tacrolimus. Interestingly, the change of medication induced the reversibility of diabetes in $34 \%$ of the cases, particularly in those treated with life-style interventions. The fact that established diabetes may reverse with a change in medication clearly indicates that $\beta$-cells are more resilient than considered previously. More studies in this field are needed to further confirm this therapeutically option.

\section{Conclusion}

PTDM is a frequent and severe complication after renal transplantation. Also, prediabetes is highly prevalent in this population. Both entities increase the risk for cardiovascular events in renal transplant patients. Recent studies reinforce the common links between PTDM and T2DM. The identification of patients at risk, particularly in the waiting list, is crucial to prevent the disease and its complications. More clinical trials are needed to establish the best therapeutic approach to reduce the incidence of PTDM and to treat established disease with the newer anti-diabetic agents.

\section{Acknowledgements}

Raúl Morales Febles has a grant PFIS FI17/03003 of the InstitutodeSaludCarlosIII,NataliaNegrínMenahasaPTA2016/13193/I, MINECO, Armando Torres Ramírez (PI19/01187), Instituto de Tecnologías Biométicas (ITB), University of La Laguna, the IMBRAIN project for support (FP7-RE6-POT-2012-CT2012-31637IMBRAIN) funded under the 7th Frameworks Programme capacities. EP is a researcher of the Programme Ramón y Cajal (Grant No. RYC-2014-16573). Red de Investigación Renal (REDinREN) (Grant No. RD16/0009/0031).

\section{Conflict of Interest Statement}

The authors have no conflicts of interest to declare.

\section{Funding Sources}

PFIS FI17/03003 of the Instituto de Salud Carlos III.

\section{Author Contributions}

A.E.R.R., E.P., and M.H. were involved in the conception design and drafted the manuscript. A.E.R.R. prepared figures. All edited and revised the manuscript and approved the final version of the manuscript.

\section{References}

1 Davidson JA, Wilkinson A. New-onset diabetes after transplantation 2003 International consensus guidelines: an endocrinologist's view. Diabetes Care. 2004 Mar;27(3):805-12.

2 Hagen M, Hjelmesaeth J, Jenssen T, Morkrid L, Hartmann A. A 6-year prospective study on new onset diabetes mellitus, insulin release and insulin sensitivity in renal transplant recipients. Nephrol Dial Transplant. 2003 Oct; 18(10):2154-9.

3 Seoane-Pillado MT, Pita-Fernández S, Valdés-Cañedo F, Seijo-Bestilleiro R, PértegaDíaz S, Fernández-Rivera $C$, et al. Incidence of cardiovascular events and associated risk factors in kidney transplant patients: a competing risks survival analysis. BMC Cardiovasc Disord. 2017 Mar 7;17(1):72.

4 American Diabetes Association. Diagnosis and classification of diabetes mellitus. Diabetes Care. 2005;28(Suppl 1):S37-42.
5 Chakkera HA, Weil EJ, Castro J, Heilman RL, Reddy KS, Mazur MJ, et al. Hyperglycemia during the immediate period after kidney transplantation. Clin J Am Soc Nephrol. 2009; 4(4):853-9.

6 Chakkera HA, Weil EJ, Castro J, Heilman RL, Reddy KS, Mazur MJ, et al. Hyperglycemia during the immediate period after kidney transplantation. Clin J Am Soc Nephrol. 2009 Apr;4(4):853-9.

7 American Diabetes Association. 2. Classifications and diagnosis of diabetes: standards of medical care in diabetes: 2019. Diabetes Care. 2019 Jan;42(Suppl 1):S13-28.

8 Eide IA, Halden TA, Hartmann A, Åsberg A, Dahle DO, Reisæter AV, et al. Limitations of hemoglobin Alc for the diagnosis of posttransplant diabetes mellitus. Transplantation. 2015 Mar;99(3):629-35.
9 Fishbane S, Spinowitz B. Update on anemia in ESRD and earlier stages of CKD: core curriculum 2018. Am J Kidney Dis. 2018 Mar;71(3): 423-35.

10 EL Okel AZ, El-Arbagy AR, Yassein YS, Khodir SZ, El Sayed Kasem H. Effect of erythropoietin treatment on hemoglobin Alc levels in diabetic patients with chronic kidney disease. J Egypt Soc Nephrol Transplant. 2019;19:86-94.

$11 \mathrm{Ng} \mathrm{JM}$, Cooke M, Bhandari S, Atkin SL, Kilpatrick ES. The effect of iron and erythropoietin treatment on the A1C of patients with diabetes and chronic kidney disease. Diabetes Care. 2010 Nov;33(11):2310-3.

12 Ussif AM, Åsberg A, Halden TAS, Nordheim E, Hartmann A, Jenssen T. Validation of diagnostic utility of fasting plasma glucose and $\mathrm{HbAlc}$ in stable renal transplant recipients one year after transplantation. BMC Nephrol. 2019 Jan 10;20(1):12. 
13 Porrini EL, Díaz JM, Moreso F, Delgado Mallén PI, Silva Torres I, Ibernon M, et al. Clinical evolution of post-transplant diabetes mellitus. Nephrol Dial Transplant. 2016 Mar; 31(3):495-505.

14 Caillard S, Eprinchard L, Perrin P, Braun L, Heibel F, Moreau F, et al. Incidence and risk factors of glucose metabolism disorders in kidney transplant recipients: role of systematic screening by oral glucose tolerance test. Transplantation. 2011 Apr 15;91(7):757-64.

15 Cosio FG, Kudva Y, van der Velde M, Larson TS, Textor SC, Griffin MD, et al. New onset hyperglycemia and diabetes are associated with increased cardiovascular risk after kidney transplantation. Kidney Int. 2005 Jun; 67(6):2415-21.

16 Lv C, Chen M, Xu M, Xu G, Zhang Y, He S, et al. Influencing factors of new-onset diabetes after a renal transplant and their effects on complications and survival rate. PLoS One. 2014 Jun 9;9(6):e99406.

17 Al-Ghareeb SM, El-Agroudy AE, Al Arrayed SM, Al Arrayed A, Alhellow HA. Risk factors and outcomes of new-onset diabetes after transplant: single-centre experience. Exp Clin Transplant. 2012 Oct;10(5):458-65.

18 Sarno G, Muscogiuri G, De Rosa P. New-onset diabetes after kidney transplantation: prevalence, risk factors, and management. Transplantation. 2012 Jun 27;93(12):118995.

19 Yeh H, Lin C, Li YR, Yen CL, Lee CC, Chen JS, et al. Temporal trends of incident diabetes mellitus and subsequent outcomes in patients receiving kidney transplantation: a national cohort study in Taiwan. Diabetol Metab Syndr. 2020 Apr 28;12:34.

20 Khong MJ, Chong CP. Prevention and management of new-onset diabetes mellitus in kidney transplantation. Neth J Med. 2014 Apr;72(3):127-34.

21 Yates CJ, Fourlanos S, Hjelmesaeth J, Colman PG, Cohney SJ. New-onset diabetes after kidney transplantation-changes and challenges. Am J Transplant. 2012 Apr;12(4):820-8.

22 Al Saran K, Elsayed S, Sabry A, Hamada M. Obesity and metabolic syndrome in hemodialysis patients: single center experience. Saudi J Kidney Dis Transpl. 2011;22(6):1193-8.

23 Jalalzadeh M, Mohammadi R, Mirzamohammadi F, Ghadiani MH. Prevalence of metabolic syndrome in a hemodialysis population. Iran J Kidney Dis. 2011;5(4):248-54.

24 Tu SF, Chou YC, Sun CA, Hsueh SC, Yang T. The prevalence of metabolic syndrome and factors associated with quality of dialysis among hemodialysis patients in Southern Taiwan. Glob J Health Sci. 2012;4(5):53-62.

25 Bayer ND, Cochetti PT, Anil Kumar MS, Teal V, Huan Y, Doria C, et al. Association of metabolic syndrome with development of newonset diabetes after transplantation. Transplantation. 2010 Oct 27;90(8):861-6.
26 de Lucena DD, de Sá JR, Medina-Pestana JO, Rangel ÉB. Modifiable variables are major risk factors for posttransplant diabetes mellitus in a time-dependent manner in kidney transplant: an observational cohort study. J Diabetes Res. 2020 Mar 18;2020:20201938703.

27 Bergrem HA, Valderhaug TG, Hartmann A, Hjelmesaeth J, Leivestad T, Bergrem H, et al. Undiagnosed diabetes in kidney transplant candidates: a case-finding strategy. Clin J Am Soc Nephrol. 2010 Apr;5(4):616-22.

28 Bonet J, Martinez-Castelao A, Bayés B. Metabolic syndrome in hemodialysis patients as a risk factor for new-onset diabetes mellitus after renal transplant: a prospective observational study. Diabetes Metab Syndr Obes. 2013 Sep 18;6:339-46.

29 Sharif A, Baboolal K. Risk factors for new-onset diabetes after kidney transplantation. Nat Rev Nephrol. 2010 Jul;6(7):415-23.

30 Pham PT, Pham PM, Pham SV, Pham PA, Pham PC. New onset diabetes after transplantation (NODAT): an overview. Diabetes Metab Syndr Obes. 2011;4:175-86.

31 Vincenti F, Charpentier B, Vanrenterghem Y, Rostaing L, Bresnahan B, Darji P, et al. A phase III study of belatacept-based immunosuppression regimens versus cyclosporine in renal transplant recipients (BENEFIT study). Am J Transplant. 2010;10(3):535-46.

32 Durrbach A, Pestana JM, Pearson T, Vincenti F, Garcia VD, Campistol J, et al. A phase III study of belatacept versus cyclosporine in kidney transplants from extended criteria donors (BENEFIT-EXT study). Am J Transplant. 2010;10(3):547-57.

33 Wen X, Casey MJ, Santos AH, Hartzema A, Womer KL. Comparison of utilization and clinical outcomes for belatacept- and tacrolimus-based immunosuppression in renal transplant recipients. Am J Transplant. 2016 Nov;16(11):3202-11.

34 DeFronzo RA. Pathogenesis of type 2 diabetes mellitus. Med Clin North Am. 2004 Jul;88(4): 787-835.ix.

35 Leahy JL. Pathogenesis of type 2 diabetes mellitus. Arch Med Res. 2005 May-Jun;36(3): 197-209.

36 Reaven GM. Banting lecture 1988. Role of insulin resistance in human disease. Diabetes. 1988;37(12):1595-607.

37 Kahn CR. Insulin resistance, insulin sensitivity, and insulin unresponsiveness: a necessary distinction. Metabolism. 1978;27:1893-902.

38 David M, Nathan MD. Clinical practice. Initial management of glycemia in type 2 diabetes mellitus. N Engl J Med. 2002;347(17): 1342-9.

39 Andrew M. Freeman; nicholas pennings. Insulin resistance. Treasure Island, FL: StatPearls Publishing; 2020 Jan.

40 Roberts CK, Hevener AL, Barnard RJ. Metabolic syndrome and insulin resistance: underlying causes and modification by exercise training. Compr Physiol. 2013 Jan;3(1):1-58.
41 Hornum M, Jørgensen KA, Hansen JM, Nielsen FT, Christensen KB, Mathiesen ER, et al. New-onset diabetes mellitus after kidney transplantation in Denmark. Clin J Am Soc Nephrol. 2010 Apr;5(4):709-16.

42 Jørgensen MB, Hornum M, van Hall G, Bistrup C, Hansen JM, Mathiesen ER, et al. The impact of kidney transplantation on insulin sensitivity. Transpl Int. 2017 Mar [cited 2019 Jun 11];30(3):295-304.];

43 Ferrannini E, Gastaldelli A, Miyazaki Y, Matsuda M, Mari A, DeFronzo RA. Beta cell function in subjects spanning the range from normal glucose tolerance to overt diabetes mellitus: a new analysis. J Clin Endocrinol Metab. 2005 Jan;90(1):493-500.

44 DeFronzo RA, Abdul-Ghani MA. Preservation of $\beta$-cell function: the key to diabetes prevention. J Clin Endocrinol Metab. 2011 Aug; 96(8):2354-66.

45 DeFronzo RA, Alvestrand A, Smith D, Hendler R, Hendler E, Wahren J. Insulin resistance in uremia. J Clin Invest. 1981;67(2): 563-8.

46 Ford ES, Li C, Sattar N. Metabolic syndrome and incident diabetes: current state of the evidence. Diabetes Care. 2008 Sep;31(9):1898904

47 Cerf ME. Beta cell dysfunction and insulin resistance. Front Endocrinol. 2013 Mar 27;4:37.

48 Fu Z, Gilbert ER, Liu D. Regulation of insulin synthesis and secretion and pancreatic betacell dysfunction in diabetes. Curr Diabetes Rev. 2013 Jan 1;9(1):25-53.

49 Leahy JL. $\beta$ cell dysfunction with chronic hyperglycaemia in type 2 diabetes: the "overworked $\beta$ cells" hypothesis. Diabetes Rev. 1996;4:298-319.

50 Butler AE, Janson J, Bonner-Weir S, Ritzel R, Rizza RA, Butler PC. Beta-cell deficit and increased beta-cell apoptosis in humans with type 2 diabetes. Diabetes. 2003 Jan;52(1):102-10.

51 Yoon KH, Ko SH, Cho JH, Lee JM, Ahn YB, Song $\mathrm{KH}$, et al. Selective beta-cell loss and alpha-cell expansion in patients with type 2 diabetes mellitus in Korea. J Clin Endocrinol Metab. 2003 May;88(5):2300-8.

52 Rahier J, Guiot Y, Goebbels RM, Sempoux C, Henquin JC. Pancreatic beta-cell mass in European subjects with type 2 diabetes. Diabetes Obes Metab. 2008 Nov;10(Suppl 4):32-42.

53 Talchai C, Xuan S, Lin HV, Sussel L, Accili D. Pancreatic $\beta$ cell dedifferentiation as a mechanism of diabetic $\beta$ cell failure. Cell. 2012 Sep 14;150(6):1223-34.

54 Bensellam M, Jonas JC, Laybutt DR. Mechanisms of $\beta$-cell dedifferentiation in diabetes: recent findings and future research directions. J Endocrinol. 2018 Feb;236(2):R10943.

55 Wang H, Brun T, Kataoka K, Sharma AJ, Wollheim CB. MAFA controls genes implicated in insulin biosynthesis and secretion. Diabetologia. 2007 Feb;50(2):348-58. 
56 Kaneto H, Miyatsuka T, Kawamori D, Yamamoto K, Kato K, Shiraiwa T, et al. PDX-1 and MafA play a crucial role in pancreatic betacell differentiation and maintenance of mature beta-cell function. Endocr J. 2008 May; 55(2):235-52.

57 Zhang C, Moriguchi T, Kajihara M, Esaki R, Harada A, Shimohata H, et al. MafA is a key regulator of glucose-stimulated insulin secretion. Mol Cell Biol. 2005 Jun;25(12):4969-76.

58 Kitamura T. The role of FOXO1 in $\beta$-cell failure and type 2 diabetes mellitus. Nat Rev Endocrinol. 2013 Oct;9(10):615-23.

59 Guo S, Dai C, Guo M, Taylor B, Harmon JS, Sander $\mathrm{M}$, et al. Inactivation of specific $\beta$ cell transcription factors in type 2 diabetes. J Clin Invest. 2013 Aug;123(8):3305-16.

60 Wang Z, York NW, Nichols CG, Remedi MS. Pancreatic $\beta$ cell dedifferentiation in diabetes and redifferentiation following insulin therapy. Cell Metab. 2014 May 6;19(5):872-82.

61 Spijker HS, Ravelli RB, Mommaas-Kienhuis AM, van Apeldoorn AA, Engelse MA, Zaldumbide $\mathrm{A}$, et al. Conversion of mature hu$\operatorname{man} \beta$-cells into glucagon-producing $\alpha$-cells. Diabetes. 2013 Jul;62(7):2471-80.

62 Porrini E, Delgado P, Alvarez A, Cobo M, Pérez L, González-Posada JM, et al. The combined effect of pre-transplant triglyceride levels and the type of calcineurin inhibitor in predicting the risk of new onset diabetes after renal transplantation. Nephrol Dial Transplant. 2008 Apr;23(4):1436-41.

63 Redmon JB, Olson LK, Armstrong MB Greene MJ, Robertson RP. Effects of tacrolimus (FK506) on human insulin gene expression, insulin mRNA levels, and insulin secretion in HIT-T15 cells. J Clin Invest. 1996 Dec 15;98(12):2786-93.

64 Hernández-Fisac I, Pizarro-Delgado J, Calle C, Marques M, Sánchez A, Barrientos A, et al. Tacrolimus-induced diabetes in rats courses with suppressed insulin gene expression in pancreatic islets. Am J Transplant. 2007 Nov; 7(11):2455-62.

65 Li QY, Li F, Sun JH, Chi YY, Yin HS, Liu SQ, et al. Mechanisms of diabetes mellitus induced with FK506 in SD rats models. Immunopharmacol Immunotoxicol. 2009;31(4): $675-81$.

66 Morris R. Cyclosporin A, FK506, and rapamycin: binding to immunophilins and biological action. Chem Immunol. $1994 \mathrm{Dec}$ 59(6):128-55

67 Rodriguez-Rodriguez AE, Triñanes J, Velazquez-Garcia S, Porrini E, Vega Prieto MJ, Diez Fuentes ML, et al. The higher diabetogenic risk of tacrolimus depends on pre-existing insulin resistance. A study in obese and lean Zucker rats. Am J Transplant. 2013 Jul; 13(7):1665-75

68 Triñanes J, Rodriguez-Rodriguez AE, BritoCasillas Y, Wagner A, De Vries APJ, Cuesto $\mathrm{G}$, et al. Deciphering tacrolimus-induced toxicity in pancreatic $\beta$ cells. Am J Transplant. 2017 Nov;17(11):2829-40.
69 Wissing KM, Abramowicz D, Weekers L, Budde K, Rath T, Witzke O, et al. Prospective randomized study of conversion from tacrolimus to cyclosporine A to improve glucose metabolism in patients with posttransplant diabetes mellitus after renal transplantation. Am J Transplant. 2018 Jul;18(7):1726-34.

70 Ghisdal L, Bouchta NB, Broeders N, Crenier L, Hoang AD, Abramowicz D, et al. Conversion from tacrolimus to cyclosporine A for new-onset diabetes after transplantation: a single-centre experience in renal transplanted patients and review of the literature. Transpl Int. 2008 Feb;21(2):146-51.

71 Aghdasi B, Ye K, Resnick A, Huang A, Ha HC, Guo X, et al. FKBP12, the 12-kDa FK506binding protein, is a physiologic regulator of the cell cycle. Proc Natl Acad Sci U S A. 2001 Feb 27;98(5):2425-30.

72 Wang T, Li BY, Danielson PD, Shah PC, Rockwell S, Lechleider RJ, et al. The immunophilin FKBP12 functions as a common inhibitor of the TGF beta family type I receptors. Cell. 1996 Aug 9;86(3):435-44.

73 Yao D, Doré JJJr, Leof EB. FKBP12 is a negative regulator of transforming growth factorbeta receptor internalization. J Biol Chem. 2000 Apr 28;275(17):13149-54.

74 Santulli G, Pagano G, Sardu C, Xie W, Reiken S, D'Ascia SL, et al. Calcium release channel RyR2 regulates insulin release and glucose homeostasis. J Clin Invest. 2015 May;125(11): 4316-78.

75 Rodriguez-Rodriguez AE, Donate-Correa J, Rovira J, Cuesto G, Luis-Ravelo D, Fernandes MX, et al. Inhibition of the mTOR pathway: a new mechanism of $\beta$ cell toxicity induced by tacrolimus. Am J Transplant. 2019 Dec; 19(12):3240-9.

76 Triñanes J, Ten Dijke P, Groen N, Hanegraaf $\mathrm{M}$, Porrini E, Rodriguez-Rodriguez AE, et al. Tacrolimus-Induced BMP/SMAD signaling associates with metabolic stress-activated FOXO1 to trigger $\beta$-cell failure. Diabetes. 2020 Feb;69(2):193-204.

77 Midtvedt K, Hartmann A, Hjelmesaeth J, Lund $\mathrm{K}$, Bjerkely BL. Insulin resistance is a common denominator of post-transplant diabetes mellitus and impaired glucose tolerance in renal transplant recipients. Nephrol Dial Transplant. 1998;13(2):427-31.

78 Ekstrand AV, Eriksson JG, Grönhagen-Riska C, Ahonen PJ, Groop LC. Insulin resistance and insulin deficiency in the pathogenesis of posttransplantation diabetes in man. Transplantation. 1992;53(3):563-9.

79 Oterdoom LH, de Vries AP, Gansevoort RT, van Son WJ, van der Heide JJ, Ploeg RJ, et al. Determinants of insulin resistance in renal transplant recipients. Transplantation. 2007; 83(1):29-35.

80 Christiansen E, Andersen HB, Rasmussen K, Christensen NJ, Olgaard K, Kirkegaard P, et al. Pancreatic beta-cell function and glucose metabolism in human segmental pancreas and kidney transplantation. Am J Physiol. 1993;264(3 Pt 1):E441-9.
81 Markell M. New-onset diabetes mellitus in transplant patients: pathogenesis, complications and management. Am J Kidney Dis. 2004;6:953-65.

82 Ozbay LA, Møller N, Juhl C, Bjerre M, Carstens J, Rungby J, et al. The impact of calcineurin inhibitors on insulin sensitivity and insulin secretion: a randomized crossover trial in uraemic patients. Diabet Med. 2012 Dec 29(12):e440-4.

83 Chakkera HA, Kudva Y, Kaplan B. Calcineurin inhibitors: pharmacologic mechanisms impacting both insulin resistance and insulin secretion leading to glucose dysregulation and diabetes mellitus. Clin Pharmacol Ther. 2017 Jan;101(1):114-20.

84 Lamming DW, Ye L, Katajisto P, Goncalves MD, Saitoh M, Stevens DM, et al. Rapamycininduced insulin resistance is mediated by mTORC2 loss and uncoupled from longevity. Science. 2012;335(6076):1638-43.

85 Deblon N, Bourgoin L, Veyrat-Durebex C, Peyrou M, Vinciguerra M, Caillon A, et al. Chronic mTOR inhibition by rapamycin induces muscle insulin resistance despite weight loss in rats. Br J Pharmacol. 2012;165(7): 2325-40.

86 Cosio FG, Kudva Y, van der Velde M, Larson TS, Textor SC, Griffin MD, et al. New onset hyperglycemia and diabetes are associated with increased cardiovascular risk after kidney transplantation. Kidney Int. 2005;67(6): 2415-21.

87 Kasiske BL, Snyder JJ, Gilbertson D, Matas AJ. Diabetes mellitus after kidney transplantation in the United States. Am J Transplant. 2003; 3(2): 178-85.

88 Yeh H, Lin C, Li YR, Yen CL, Lee CC, Chen JS, et al. Temporal trends of incident diabetes mellitus and subsequent outcomes in patients receiving kidney transplantation: a national cohort study in Taiwan. Diabetol Metab Syndr. 2020 Apr 28;12:34.

89 Porrini E, Díaz JM, Moreso F, Lauzurrica R, Ibernon M, Torres IS, et al. Prediabetes is a risk factor for cardiovascular disease following renal transplantation. Kidney Int. 2019 Dec 1 [cited 2020 Mar 25];96(6):1374-80

90 Scappaticcio L, Maiorino MI, Bellastella G, Giugliano D, Esposito K. Insights into the relationships between diabetes, prediabetes, and cancer. Endocrine. 2017 May;56(2):231-9.

91 Gallagher EJ, LeRoith D. Obesity and diabetes: the increased risk of cancer and cancerrelated mortality. Physiol Rev. 2015 Jul;95(3): 727-48.

92 Cignarelli A, Genchi VA, Caruso I, Natalicchio A, Perrini S, Laviola L, et al. Diabetes and cancer: pathophysiological fundamentals of a "dangerous affair". Diabetes Res Clin Pract. 2018 Sep;143:378-88.

93 Torres A, Hernández D, Moreso F, Serón D, Burgos MD, Pallardó LM, et al. Randomized controlled trial assessing the impact of tacrolimus versus cyclosporine on the incidence of posttransplant diabetes mellitus. Kidney Int Rep. 2018 Jul 11;3(6):1304-15. 
94 Knowler WC, Barrett-Connor E, Fowler SE, Hamman RF, Lachin JM, Walker EA, et al. Reduction in the incidence of type 2 diabetes with lifestyle intervention or metformin (DPP study). N Engl J Med. 2002 Feb 7;346(6):393403.

95 Pan XR, Li GW, Hu YH, Wang JX, Yang WY, An ZX, et al. Effects of diet and exercise in preventing NIDDM in people with impaired glucose tolerance: the Da Qing IGT and Diabetes Study. Diabetes Care. 1997 Apr;20(4): 537-44.

96 Tuomilehto J, Lindström J, Eriksson JG, Valle TT, Hämäläinen H, Ilanne-Parikka P, et al. Prevention of type 2 diabetes mellitus by changes in lifestyle among subjects with impaired glucose tolerance. N Engl J Med. 2001 May;344(18):1343-50.

97 Sharif A, Hecking M, De Vries AP, Porrini E, Hornum M, Rasoul-Rockenschaub S, et al. Proceedings from an international consensus meeting on posttransplantation diabetes mellitus: recommendations and future directions. Am J Transplant. 2014;14(9):19922000.

98 Hecking M, Haidinger M, Döller D, Werzowa J, Tura A, Zhang J, et al. Early basal insulin therapy decreases new-onset diabetes after renal transplantation. J Am Soc Nephrol. 2012 Apr;23(4):739-49.
99 Werzowa JM, Säemann MD, Mohl A, Bergmann M, Kaltenecker CC, Brozek W, et al. A randomized controlled trial-based algorithm for insulin-pump therapy in hyperglycemic patients early after kidney transplantation. PLoS One. 2018 Mar 1;13(3): e0193569.

100 Strøm Halden TA, Åsberg A, Vik K, Hartmann A, Jenssen T. Short-term efficacy and safety of sitagliptin treatment in long-term stable renal recipients with new-onset diabetes after transplantation. Nephrol Dial Transplant. 2014 Apr [cited 2019 Nov 5]; 29(4):926-33.

101 Werzowa J, Hecking M, Haidinger M, Lechner F, Döller D, Pacini G, et al. Vildagliptin and pioglitazone in patients with impaired glucose tolerance after kidney transplantation: a randomized, placebo-controlled clinical trial. Transplantation. 2013;95(3):45662.

102 Haidinger M, Werzowa J, Hecking M, Antlanger M, Stemer G, Pleiner J, et al. Efficacy and safety of vildagliptin in new-onset diabetes after kidney transplantation: a randomized, double-blind, placebo-controlled trial. Am J Transplant. 2014 Jan;14(1):11523.
103 Halden TA, Egeland EJ, Åsberg A, Hartmann A, Midtvedt K, Khiabani HZ, et al. GLP-1 restores altered insulin and glucagon secretion in posttransplantation diabetes. Diabetes Care. 2016 Apr;39(4):61724.

104 Pinelli NR, Patel A, Salinitri FD. Coadministration of liraglutide with tacrolimus in kidney transplant recipients: a case series. Diabetes Care. 2013:36(10);e171-2.

105 Strøm Halden TA, Kvitne KE, Midtvedt K, Rajakumar L, Robertsen I, Brox J, et al. Efficacy and safety of empagliflozin in renal transplant recipients with posttransplant diabetes mellitus. Diabetes Care. 2019 Jun 1; 42(6):1067-74.

106 Schwaiger E, Burghart L, Signorini L, Ristl R, Kopecky C, Tura A, et al. Empagliflozin in posttransplantation diabetes mellitus: a prospective, interventional pilot study on glucose metabolism, fluid volume, and patient safety. Am J Transplant. 2019 Mar 1;19(3): 907-19.

107 Morales Febles R, Negrín Mena N, Rodríguez-Rodríguez AE, Díaz Martín L, González Rinne F, Marrero Miranda D, et al. Exercise and Prediabetes after Renal Transplantation (EXPRED): Protocol Description. Nephron. 2021;145(1):55-62. 